\title{
FREN DİSK SICAKLIĞININ FRENLEME PERFORMANSINA ETKİsí
}

\author{
Mehmet ERDEM ${ }^{1}$, Duran ALTIPARMAK ${ }^{2}$ \\ ${ }^{1}$ Makine ve Metal Teknolojileri Bölümü, Kütahya Teknik Bilimler MYO, Dumlupınar Üniversitesi, Germiyan \\ Kampüsü, Kütahya. \\ ${ }^{2}$ Otomotiv Mühendisliği Bölümü, Teknoloji Fakültesi, Gazi Üniversitesi, Teknikokullar/Ankara. \\ mehmet.erdem@dpu.edu.tr, duranal@gazi.edu.tr
}

(Geliş/Received: 02.04.2013; Kabul/Accepted: 27.03.2014)

\section{ÖZET}

$\mathrm{Bu}$ deneysel çalışmada, fren disk sıcaklıklarındaki artışın taşıtın frenleme performansına etkileri araştırılmıştır. $\mathrm{Bu}$ amaçla, frenleme performansının en önemli göstergesi olan durma mesafesi testleri yapılmıştır. Testler, bir hafif ticari taşıtta, değişik disk sıcaklıkları, pedal kuvvetleri, taşıt yükleri ve başlangıç hızlarında gerçekleştirilmiştir. Yapılan fren etkinliği test sonuçları, fren disklerindeki sıcaklık artışının taşıtın frenleme mesafesini olumsuz etkilediğini göstermiştir. Farklı pedal kuvvetleri, frenleme başlangıç hızları ve taşıt yükü değişimlerine göre değerlendirilen sonuçlardan, disk sıcaklığındaki arışın frenleme mesafesini artırdığı gözlenmiştir. Tipik bir yol testi sonucu olarak; $80 \mathrm{~km} / \mathrm{h}$ hızla ve maksimum pedal kuvvetiyle $63^{\circ} \mathrm{C}$ fren disk sıcaklığında taşıt 44,9 m'de dururken, $298^{\circ} \mathrm{C}$ disk sicaklığında durma mesafesi $\% 17,4$ oranında artarak $52,71 \mathrm{~m}$ olarak ölçülmüştür.

Anahtar kelimeler: Frenleme performansı, yol deneyi, durma mesafesi, disk sıcaklı̆̆ı, hafif ticari taşıt

\section{THE EFFECT OF BRAKE DISC TEMPERATURE ON BRAKING PERFORMANCE}

\begin{abstract}
In this experimental work, effect of increasing in brake disc temperature on braking performance was investigated. For this purpose, braking distance tests which the criteria of braking performance were carried out. The tests were conducted on a small-size commercial vehicle for different disc temperatures, pedal forces, the vehicle loads and for initial vehicle speeds. Test results of stopping (braking) distance were analyzed for the variation of disc temperatures. The results showed that the stopping distance is considerable increased when the disc temperature is increased for different vehicle speed and pedal forces. Typically, at the vehicle speed of 80 $\mathrm{km} / \mathrm{h}$ and maximum pedal force for $63{ }^{\circ} \mathrm{C}$ disc temperature, $44.9 \mathrm{~m}$ stopping distance was measured. When the temperature is increased as $298{ }^{\circ} \mathrm{C}$, stopping distance is increased as $52.71 \mathrm{~m}$ with the rate of $17.4 \%$ at road test.
\end{abstract}

Keywords: Braking performance, road test, stopping distance, brake disc temperature, light commercial vehicle

\section{GİRİŞ (INTRODUCTION)}

Trafik kazalarının nedenlerine yönelik yapılan araştırmalarda, sürücüye ait kusurlar ön plana çıkmakta, taşıt ve yol kusurları düşük oranlarda seyretmektedir. Taşıtların neden olduğu kazalarda ise lastik patlamasının hemen ardından fren kusurları gelmektedir [1].

Taşıtlarda aktif güvenlikle ilgili en önemli donanım fren sistemleridir. Gelişen teknolojiyle birlikte günümüz taşıtlarında konforun yanı sıra hız ve ağır ticari taşıtlardaki yük kapasitesi sürekli olarak artmakta, bu durum etkili ve güçlü fren sistemlerinin geliştirilmesi ihtiyacını doğurmaktadır. Taşıt frenleri seyir halindeki taşıtın hızını kontrol etmek ve etkili bir durma sağlayabilmek açısından yol güvenliğine doğrudan etki etmektedir [2-4].

Fren sisteminin etkinliği ve frenleme performansı taşıtın durma mesafesi ile ifade edilen önemli bir göstergedir [5]. Frenleme performansına etki eden başlıca faktörler; taşıt ağırlığı, fren sisteminin tasarımı, fren hidrolik ve mekanik aksamının durumu, 
fren sistemini etkileyebilecek çevre şartları, yol şartları, lastiklerin durumu, tekerlek ve yol yüzeyi arasındaki tutunma katsayısı olarak sıralanabilir [6-9].

Taşıtın frenleme performansını doğrudan etkileyen diğer bir faktör ise fren sistemi elemanlarının sıcaklığındaki artıştır. Frenleme anındaki yüksek sıcaklık, kampana-balata (veya disk-balata) arasında ani sürtünme kaybına (fading), erken aşınmaya, fren sıvısının buharlaşmasına, termal çatlaklara ve vibrasyona neden olabilir [10-13].

Fren kampana ve disklerinin sıcaklığı ağır ticari taşıtlar için kritik bir değerdir. Nitekim sıcaklık, frenleme etkinliğini doğrudan etkileyen bir faktördür. Sıcaklık etkisi, aşırı ısınmada daha büyük önem taşır ve bunun sik tekrar etmesi fren diskleriyle balatalar arasındaki sürtünme katsayısını azaltarak tehlikeye sokar. $\mathrm{Bu}$ olgu, fren etkinliğinin azalması (fading) olarak adlandırılır [14-16].

Fren diski veya kampanasındaki sıcaklık artışına bağlı olarak fren etkinliğinin kaybolmasına ilişkin literatürde birbirine yakın eşik değerler yer almaktadır. Satapathy ve arkadaşları [17], etkinlik kayıplarını; 'yüke bağlı etkinlik kaybı', 'hıza bağlı etkinlik kaybı' ve 'sıcaklığa bağlı etkinlik kaybı' olarak sınıflandırıp, sıcaklığa bağlı etkinlik kaybının diskli frenlerde $370^{\circ} \mathrm{C}$ 'den itibaren önemli ölçüde kendini göstereceğini ifade etmişlerdir. Bijwe ve arkadaşları [18], $300-400^{\circ} \mathrm{C}$ arasındaki sıcaklık değerlerine yükselen fren disklerinin etkinlik kaybına neden olabileceğini vurgulamışlardır. Aleksendric ve Duboka [19] ise $400^{\circ} \mathrm{C}$ civarındaki sıcaklıkların eşik değer olduğunu, disk sıcaklıklarının $600^{\circ} \mathrm{C}$ 'yi aşması halinde fren diski ile balata arasındaki sürtünme katsayısının büyük ölçüde azalması nedeniyle fren etkinliğinin tamamen kaybolacağını savunmuştur. Benzer sıcaklık eşik değerlerini telaffuz eden Lingman da [20] $900^{\circ} \mathrm{C}$ 'ye ulaşan disk sıcaklıklarının balatanın yanmasına neden olacağını belirtmiştir. Ilm ve arkadaşları [21], bir kinetik enerji simülasyonu aracılığıyla yapmış oldukları deneylerde disk yüzey sıcaklığ $150^{\circ} \mathrm{C}$ iken sürtünme katsayısının 0,55 olduğunu, $250^{\circ} \mathrm{C}$ 'ye yükselen disk yüzey sıcaklığında ise sürtünme katsayısının 0,23 olduğunu gözlemlemişlerdir.

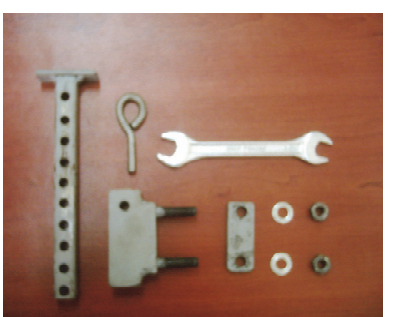

(a)

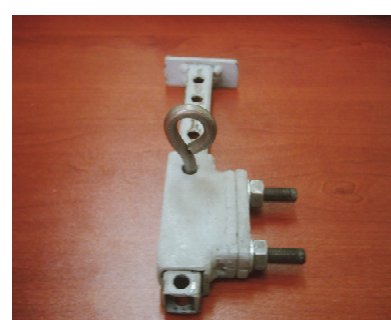

(b)
Bu çalışmada, hafif bir ticari taşıtın frenleme sırasında fren disk sıcaklıklarındaki değişimin durma mesafesine etkilerini belirlemek amaciyla yol deneyleri yapılmıştır. Deneylerde; disk sıcaklıklarının yanı sıra taşıt hızı, taşıt ağırlığı ve uygulanan pedal kuvveti değişkenleri de dikkate alınmıştır.

\section{MATERYAL VE METOT (MATERIALS AND METHOD)}

Deney taşıtı olarak Mercedes Sprinter marka 313 CDI model hafif ticari taşıt kullanılmıştır. $\mathrm{Bu}$ deney taşıtının seçilmesindeki amaç, sıcaklık etkisiyle fren etkinliği kaybı probleminin sadece ağır taşıtlar için geçerli bir problem olmadığını ortaya koymaktır.

Fren etkinliği deneyleri 1500 metre uzunluğunda 40 metre genişliğinde kuru asfalt zemine sahip trafiğe kapalı bir pistte yapılmıştır. Yol yüzeyinin sürtünme katsayısı 0,6 olarak kabul edilmiştir.

Deneyler esnasında disk sıcaklıklarının istenilen sıcaklığa ulaşıp ulaşmadığını kontrol etmek amacıyla kızılötesi prensiple çalışan ve uzaktan temassız ölçüm yapabilme özelliğine sahip olan bir sıcaklık ölçer kullanılmıştır (Şekil 1).

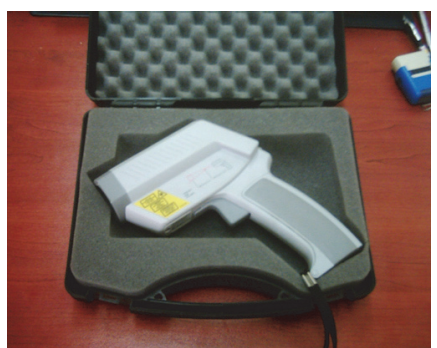

Şekil 1. Lazer sıcaklık ölçer (Laser Thermometer)

Fren etkinliği deneylerinde farklı pedal kuvveti değerlerinin durma mesafesine etkilerini gözlemleyebilmek amaciyla bir pedal kuvveti sınırlayıcı aparat geliştirilmiştir (Şekil 2-a,b). Fren pedalı tutucusuna rijit olarak bağlanan aparat, kayar mekanizmasının üzerindeki delikler ve bir pim sayesinde değişik kademelerde deneyler yapmaya imkân vermektedir (Şekil 2-c).

Şekil 2. Pedal kuvveti sınırlayıcı aparat ve fren pedalına bağlantısı (Apparatus of the pedal force limiter and installation to the brake pedal) 
Yapılan deneylerde aparatın 3 farklı kademesi kullanılmıştır. Aparatın kalibrasyonu tamburlu fren test cihazı yardımıyla yapılmış ve kademeye karşılık gelen pedal kuvveti değerleri belirlenmiştir. Buna göre, sınırlayıcı aparatın 1. kademesinde $120 \mathrm{~N}, 2$. kademesinde $260 \mathrm{~N}$ ve 3 . kademesinde $450 \mathrm{~N}$ 'luk bir kuvvet uygulandığı tespit edilmiştir [22].

Pedala uygulanan kuvveti ölçmek amaciyla dijital ekranlı pedal kuvvet sensörü (Şekil 3-a), ayrıca aracın hızı, durma mesafesi, ivme, zaman gibi verileri toplayıp, veri toplayıcı üniteye gönderen optik sensör (Şekil 3-b) kullanılmıştır. Sensörlerin algılamış olduğu taşıt hızı, ivme, durma mesafesi, pedal kuvveti gibi verileri toplayarak elektronik ortamda kaydeden ve bilgisayara aktarabilme imkânı veren veri toplama ünitesi kullanılmıştır (Şekil 3-c).

Yol deneyleri esnasında değişik yük şartları oluşturabilmek amacıyla her biri $25 \mathrm{~kg}$ olan yük malzemeleri kullanılmıştır. Yönerge her ne kadar yüklü şartların denenmesini gerektirse de bu çalışmada taşıtın farklı yükleme şartlarındaki davranışının da incelenmesi amaçlanmıştır.

Düz yol fren etkinliği deneyleri için 71/320/AT Fren Tip Onay Testleri yönergesindeki minimum şartlara uyulmuştur. Yönergenin Tip-0 ve Tip-I testlerinden esinlenerek oluşturulan deney talimatlarına göre 40, 60 ve $80 \mathrm{~km} / \mathrm{h}$ olmak üzere $3 \mathrm{~h} ı$ seçeneği, yüklü, yüksüz ve yarı yüklü olmak üzere 3 yük durumu, 3 farklı pedal kuvveti seçeneği ve 3 farklı disk sıcaklık değeri uygulanmıştır.

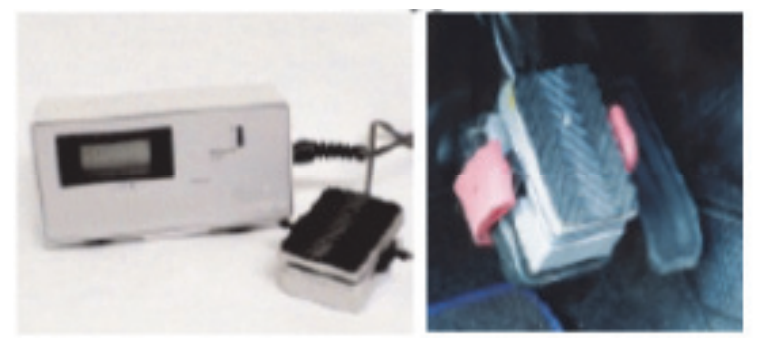

(a)
Deney ekipmanlarının deney taşıtına bağlantısının ardından yüklü şartlarda iken pisti tanımak ve bazı ön bulgular elde edebilmek amaciyla ön deneyler yapılmış, daha sonra seri deneylere geçilmiştir.

Deney talimatı çerçevesinde yüklü (3500 kg), yüksüz $(2000 \mathrm{~kg})$ ve yarı yüklü $(2750 \mathrm{~kg})$ şartlarda, 3 farklı disk sıcaklık eşiğinde ve pedal kuvveti sınırlayıcısının 3 değişik kademesinde $(450 \mathrm{~N}, 260 \mathrm{~N}$ ve $120 \mathrm{~N})$ toplam 60 durma mesafesi deneyi yapılmıştır.

Deneyler esnasında ölçülen disk sıcaklık değerleri ivme, hız, durma mesafesi gibi değerlerle birlikte veri toplama ünitesi tarafından eş zamanlı olarak kayıt altına alınmıştır.

Deneylerin yapılışına yüklü şartlarda başlanmıştır. 71/320/AT Fren Tip Onay testleri yönergesinde $100^{\circ} \mathrm{C}$ 'nin altındaki disk sıcaklıkları "Soğuk Fren" bunun üstündeki sıcaklıklar ise "Sicak Fren" olarak tanımlanmaktadır. Önceden hazırlanan deney talimatı çerçevesinde önce soğuk frenlerle $40-60$ ve $80 \mathrm{~km} / \mathrm{h}$ hızlar için 3 farklı pedal kuvveti kademesinde durma mesafesi deneyleri yapılmıştır. Daha sonra taşıtın fren diskleri ortalama $180^{\circ} \mathrm{C}$ 'ye kadar isıtılarak bir önceki deneyler tekrarlanmıştır. Son aşamada taşıtın fren diskleri ortalama $300^{\circ} \mathrm{C}^{\prime}$ ye kadar isitilarak durma mesafesi deneyleri tekrarlanmıştır. Fren disklerinin 1sitılması, taşıta uygulanan yoğun dur-kalk manevralarıyla sağlanmıştır.

Taşıtın yük şartları yarı yüklü ve yüksüz olarak ayarlandıktan sonra yukarıdaki sıra takip edilmiş ve durma mesafesi deneyleri tamamlanmıştır.
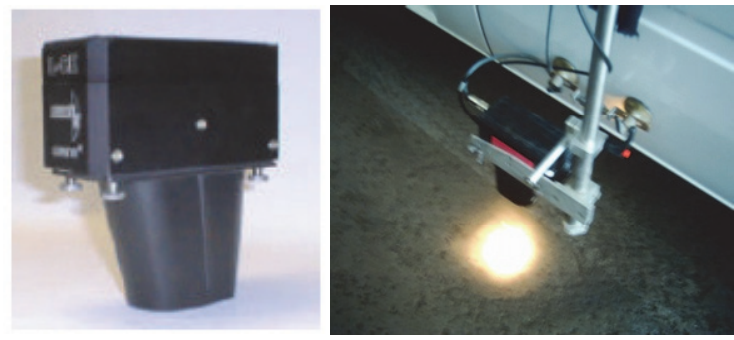

(b)

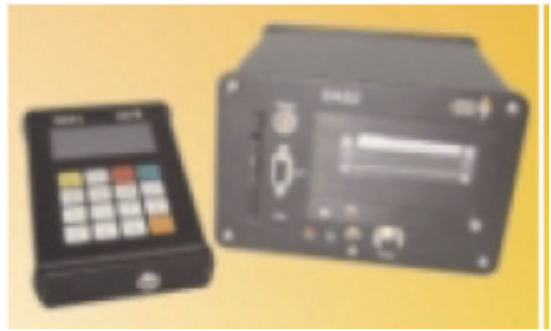

(c)

Şekil 3. Sensörler ve veri toplama ünitesi (Sensors and data acquisition unit) 


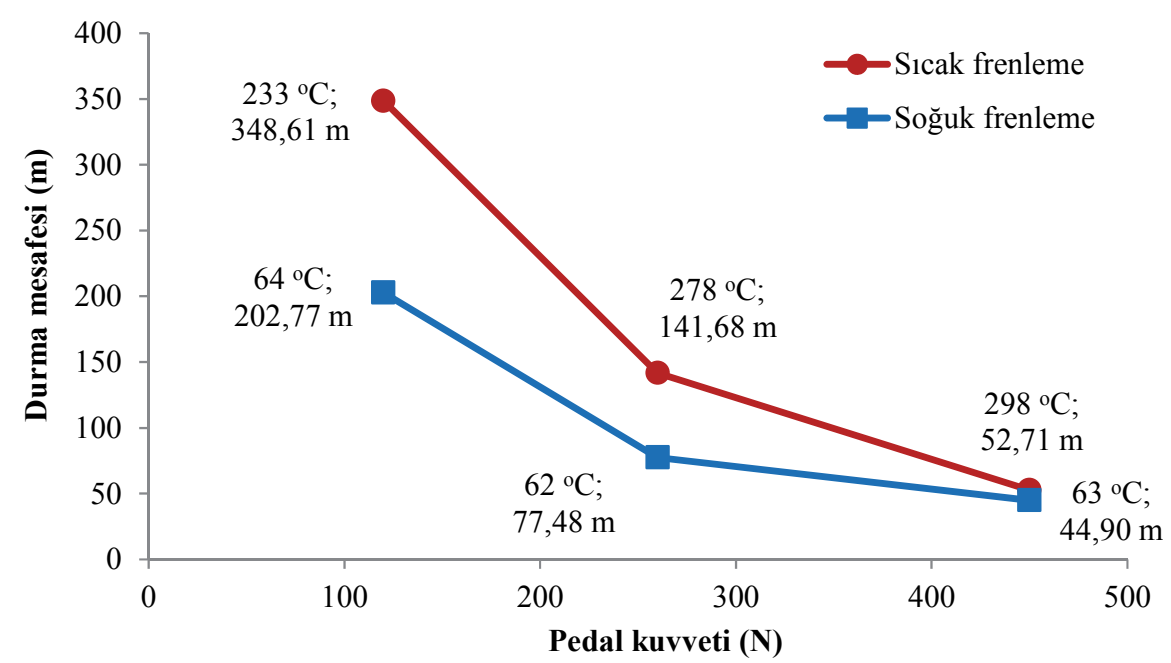

Şekil 4. Fren disk sıcaklığının durma mesafesine etkisi, $80 \mathrm{~km} / \mathrm{h}$ ve yüklü (The effect of brake disc temperature on stopping distance, $80 \mathrm{~km} / \mathrm{h}$ and laden)

\section{SONUÇLAR VE TARTIŞMA (RESULTS AND DISCUSSION)}

Fren etkinlik deneylerinin temel amaçlarından biri, fren disk sıcaklığına bağlı olarak durma mesafesinde görülen değişimleri analiz etmektir. Yapılan deneylerde, disk sıcaklıklarının artışına paralel olarak taşıtın durma mesafesinin de uzadığı görülmüştür. Şekil 4’te, frenleme öncesi hızı $80 \mathrm{~km} / \mathrm{h}$ olan yüklü taşıtın fren disklerindeki sıcaklık değişimi ve 3 farklı pedal kuvvetine (Fp) ne bağlı olarak durma mesafesi değişimleri görülmektedir. Buna göre, frenleme başlangıç hızı $80 \mathrm{~km} / \mathrm{h}$ olan taşıtın en yüksek pedal kuvvetiyle $(450 \mathrm{~N})$ frenlenmesi sonucu elde edilen durma mesafesi değerleri; disk sicaklığ $298^{\circ} \mathrm{C}$ iken $52,71 \mathrm{~m}$ olup $63{ }^{\circ} \mathrm{C}$ 'lik soğuk disklerle elde edilen durma mesafesinden $\% 17,4$ daha fazladır. Pedal kuvvetinin $260 \mathrm{~N}$ olduğu deneyde ise taşıt soğuk frenlemeye oranla \%82,8 daha geç durmuştur. En düşük pedal kuvvetinin uygulandığı 120 N'luk deneyde ise taşıt soğuk frenlemeye oranla \%71,9 daha geç durmuştur.
Durma mesafesindeki artışın nedeni, disk yüzeylerindeki isınmayla birlikte, balata-disk arasındaki sürtünme katsayısının düşmesidir. Sıcaklık artışına bağlı olarak balata malzemesinin molekülleri arasındaki bağlar genleşerek mukavemeti azalır. Bu azalmayla birlikte aşınma artar ve sürtünme katsayısı düşer. Fading olarak bilinen bu olgu, disk sıcaklığının daha büyük değerlerinde fren etkinliğinin tamamen kaybolmasına neden olmaktadır [18,19,23].

Fren disk sıcaklığındaki artışın yanı sıra, fren pedalına uygulanan kuvvetin de frenleme performansinda belirleyici bir faktör olduğu yapılan deneylerde görülmektedir. Şekil 5 'de $60 \mathrm{~km} / \mathrm{h}$ frenleme başlangıç hızına sahip taşıtın durma mesafesi değerlerinin, bir önceki deneye paralel olarak arttığı görülmektedir. 450 N'luk pedal kuvvetinin uygulandığ durma mesafesi değerleri arasındaki fark $(29,24-$ 24,28) iken 120 N'luk pedal kuvvetinin uygulandığ deneyde $(245,21-112,97)$ kadar büyük çıkmıştır.

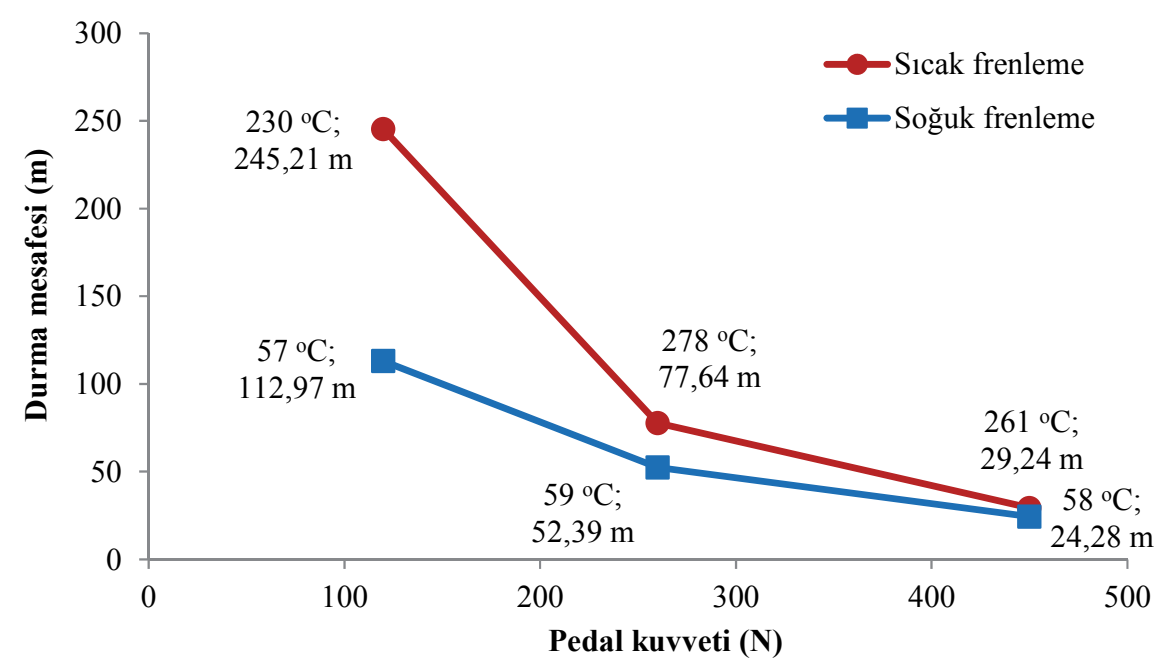

Şekil 5. Fren disk sıcaklığının durma mesafesine etkisi, $60 \mathrm{~km} / \mathrm{h}$ ve yüklü (The effect of brake disc temperature on stopping distance, $60 \mathrm{~km} / \mathrm{h}$ and laden) 


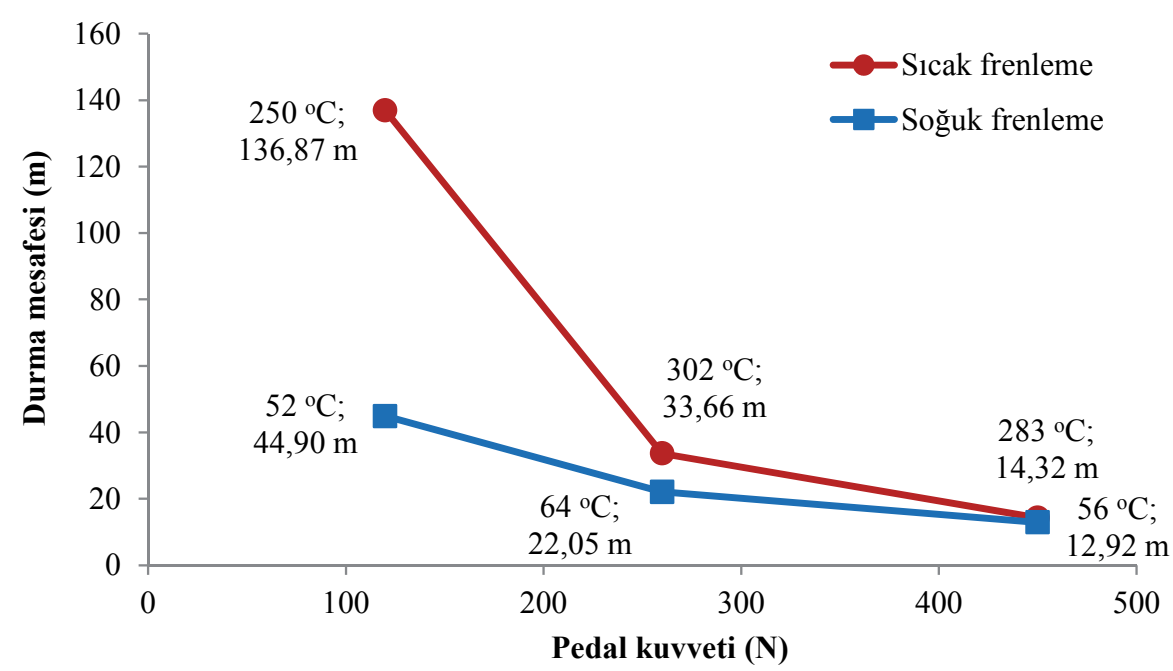

Şekil 6. Fren disk sıcaklığının durma mesafesine etkisi, $40 \mathrm{~km} / \mathrm{h}$ ve yüklü (The effect of brake disc temperature on stopping distance, $40 \mathrm{~km} / \mathrm{h}$ and laden)

Frenleme anında taşıt hızının aynı olmasıyla birlikte pedal kuvvetinin düşük olması nedeniyle daha düşük bir frenleme kuvveti oluşacağından taşıt ataleti daha etkilidir. Buna karşılık yüksek değerdeki pedal kuvvetinin uygulandı̆̆ yüksek fren gücü (frenleme kuvveti) sayesinde daha etkili frenleme ve daha kisa durma mesafesi elde edilir [24].

Şekil 6'da ise, yüklü şartlardaki taşıtın $40 \mathrm{~km} / \mathrm{h}$ frenleme öncesi hıla yapılan durma mesafesi deneylerinde disk sıcaklık değişimine bağlı durma mesafesi değerleri yer almaktadır. Burada da disk sıcaklığı arttıkça durma mesafesinin de arttığı görülmekte, ayrıca, azaltılan pedal kuvveti durma mesafesinin daha da artmasina neden olmaktadır. $[8,25]$.

Tekerlek-zemin arasında frenleme kuvvetinin optimum değerlere ulaşması tutunma-kayma ilişkisine bağlıdır. Tekerlek-zemin arasında belli bir kayma değerine ulaştıktan sonra ancak yüksek tutunma katsayılarına ulaşılabilir. Düşük pedal kuvvetlerinde bu optimizasyon sağlanamaz [24].

Taşıtın yüksüz olduğu şartlarda yapılan deneylerde, fren disk sıcaklığındaki artışa bağlı olarak elde edilen durma mesafesi değişimleri, karakteristik olarak yüklü şartlardaki deneylerin sonuçlarına büyük ölçüde paralellik göstermektedir. Şekil 7'de $80 \mathrm{~km} / \mathrm{h}$ frenleme başlangıç hızında en fazla pedal kuvveti ile yapılan deneyde taşıt $71^{\circ} \mathrm{C}$ 'lik disk sıcaklığında 38,11 m'de dururken, disk sicaklığının $255^{\circ} \mathrm{C}$ olduğu deneyde \%6,64'lük bir artışla 40,64 m'de durmuştur. Pedal kuvvetinin orta kademede olduğu deneyde disk sıcaklık artışına bağlı durma mesafesi artışı \%17,5 olurken, en düşük pedal kuvveti ile yapılan deneyde ise artış \%44,2 olarak gerçekleşmiştir.

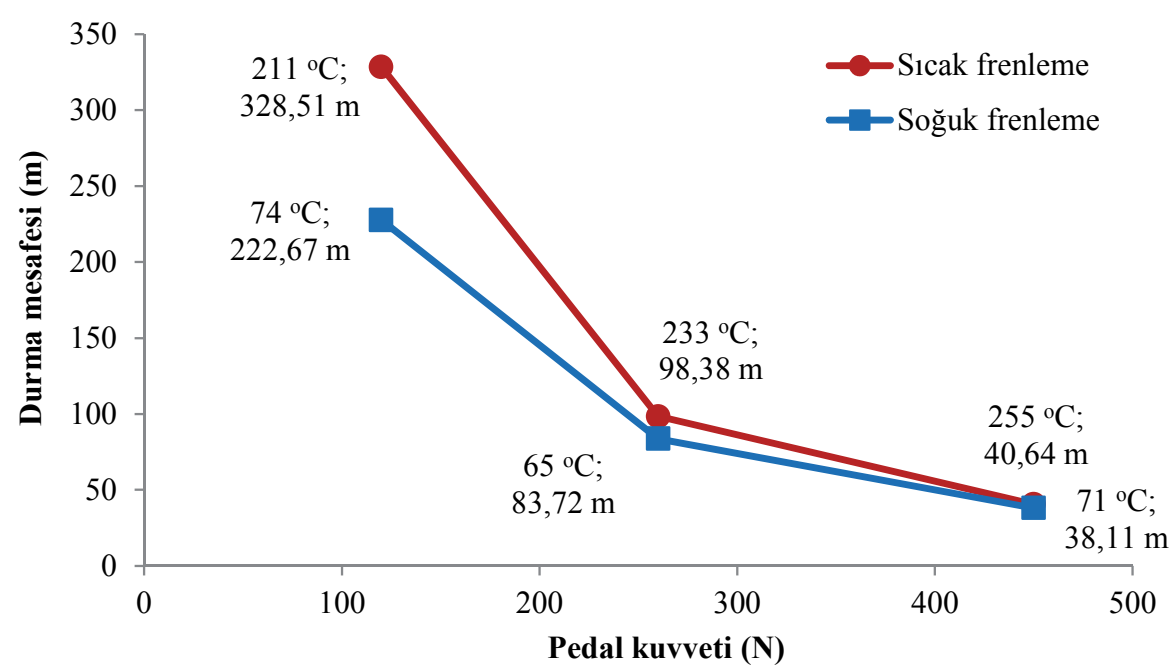

Şekil 7. Fren disk sıcaklığının durma mesafesine etkisi, $80 \mathrm{~km} / \mathrm{h}$ ve yüksüz (The effect of brake disc temperature on stopping distance, $80 \mathrm{~km} / \mathrm{h}$ and unladen) 


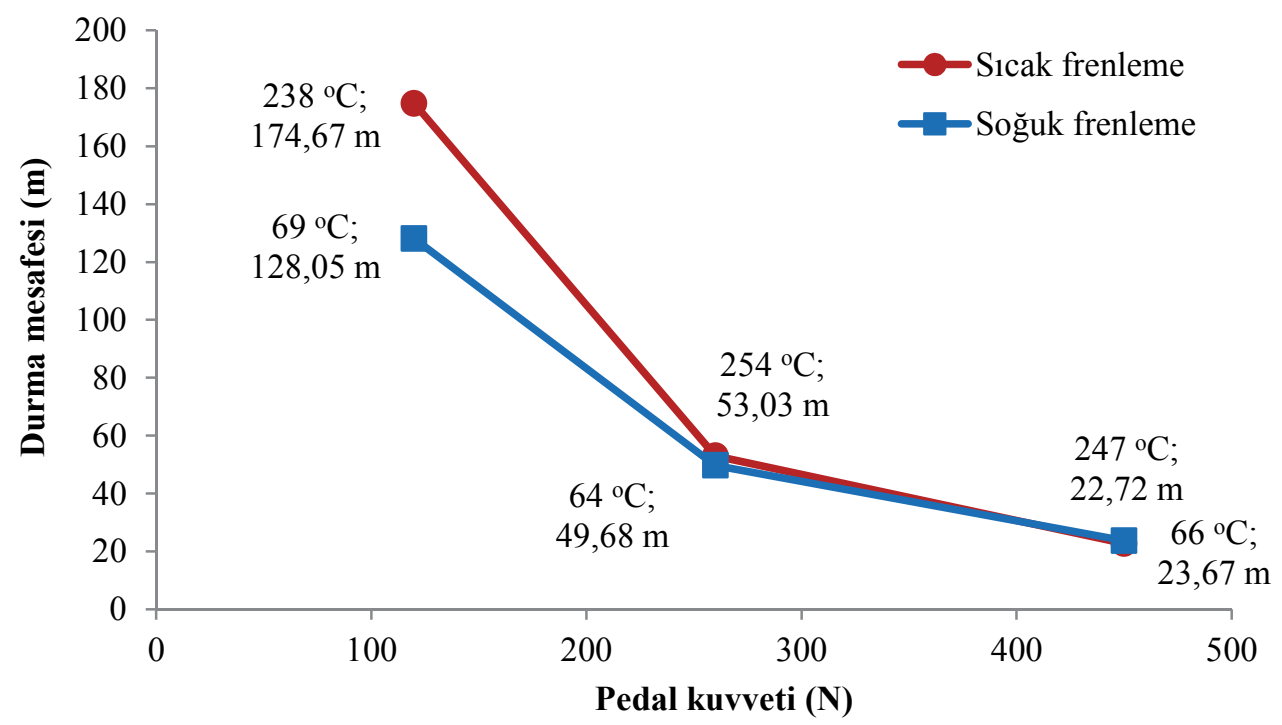

Şekil 8. Fren disk sıcaklığının durma mesafesine etkisi, $60 \mathrm{~km} / \mathrm{h}$ ve yüksüz (The effect of brake disc temperature on stopping distance, $60 \mathrm{~km} / \mathrm{h}$ and unladen)

Yüksüz şartlarda ve taşıtın frenleme başlangıç hızının $60 \mathrm{~km} / \mathrm{h}$ olduğu deneylerde de disk sicaklığındaki artışa paralel olarak durma mesafesinin de arttı̆̆ görülmektedir (Şekil 8). Bunun yanında $60 \mathrm{~km} / \mathrm{h}$ frenleme başlangıç hızında ve en fazla pedal kuvvetinin uygulandığı deneyde taşıtın sıcak frenlemede $\left(247^{\circ} \mathrm{C}\right)$ soğuk frenlemeye $\left(66^{\circ} \mathrm{C}\right)$ göre yaklaşık $1 \mathrm{~m}$ daha kısa mesafede durduğu görülmüştür. Bunun nedenleri, taşıtın fren disklerinin hıza bağlı termal soğumaya geçmesi, taşıtın yüksüz olmasından dolayı kinetik enerjisinin daha az olması ve en yüksek pedal kuvvetinin uygulanmış olması olarak siralanabilir $[8,25]$.

Şekil 9'da, yüksüz şartlarda ve $40 \mathrm{~km} / \mathrm{h}$ frenleme başlangıç hızında yapılan durma mesafesi deneyinin sonuçları görülmektedir. Buradaki bulguların da diğer hız kademesindeki bulgularla benzerlik gösterdiği belirlenmiştir.

\section{SONUÇ VE ÖNERİLER (CONCLUSION AND RECOMMENDATIONS)}

Yapılan bu deneysel çalışma, ısınan fren disklerinin taşıtın frenleme performansını olumsuz etkilediğini ortaya koymuştur. $80 \mathrm{~km} / \mathrm{h}$ hızla ve maksimum pedal kuvvetiyle yapilan durma mesafesi deneylerinde, $63^{\circ} \mathrm{C}$ olan fren disk sicaklığında taşıt 44,9 m'de dururken, disk sıcaklıklarının $298^{\circ} \mathrm{C}$ olduğu deneyde durma mesafesi \%17,4 oranında artarak $52,71 \mathrm{~m}$ olarak ölçülmüştür.

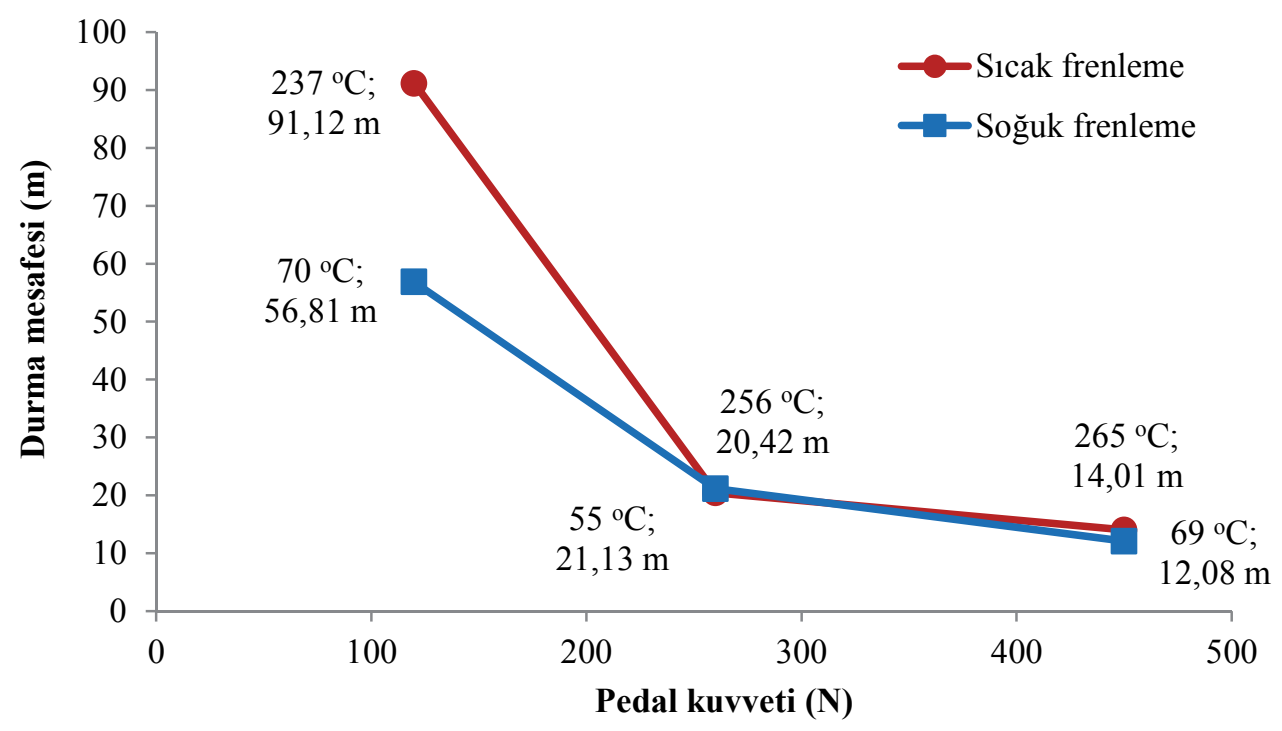

Şekil 9. Fren disk sıcaklığının durma mesafesine etkisi, $40 \mathrm{~km} / \mathrm{h}$ ve yüksüz (The effect of brake disc temperature on stopping distance, $40 \mathrm{~km} / \mathrm{h}$ and unladen) 
Pedala uygulanan kuvvetin azalması, sıcaklık artışı ile birlikte durma mesafesini artırmıştır. Yukarıdaki deneyin, bir alt kademe olan 260 N'luk pedal kuvveti uygulanarak tekrarlanmasıyla ölçülen durma mesafeleri, $278^{\circ} \mathrm{C}^{\prime}$ lik sicak frenlemede, $62^{\circ} \mathrm{C}^{\prime}$ lik soğuk frenlemeye oranla \%82,8 daha fazladır.

Taşıtın ağırlığındaki artışa paralel olarak ölçülen durma mesafesi değerlerinde de artış kaydedilmiştir. En büyük pedal kuvveti $(450 \mathrm{~N})$ uygulanarak $60 \mathrm{~km} / \mathrm{h}$ ilk hızla ve yüklü durumda yapılan frenlemede ölçülen durma mesafesi, aynı şartlarda denenen yüksüz taşıtın durma mesafesinden \%28,6 daha fazladır. Bu kıyaslama $80 \mathrm{~km} / \mathrm{h}$ ilk hız için yine \%29,6 olarak ölçülmüştür. Pedal kuvvetinin 260 N'a düşürülmesiyle $80 \mathrm{~km} / \mathrm{h}$ ilk hızla denenen yüklü taşıtın durma mesafesi, yüksüz taşıtın durma mesafesinden \%44 daha fazla ölçülmüştür.

Deneysel çalışmada ortaya konulan fren etkinliği kaybının en önemli nedeni fren disklerindeki sıcaklık artışıdır. Taşıt hızının, özellikle yokuş aşağı inişlerde servis freni ile kontrol edilmesi, yani sürekli frenleme ile fren enerjisinin artması, disk/kampana sıcaklıklarının artışını tetikleyen en önemli faktördür. Bunu önlemek amacıyla, taşıtın kinetik enerjisinin büyük bir bölümünü yutarak servis frenlerini sürekli soğuk ve işletmeye hazır halde tutan yavaşlatıcı (retarder) kullanılması, sorunun en önemli çözüm kaynağıdır.

Benzer bir çalışmanın; yüksek tonajlı araçlarda ve daha yüksek kampana/disk sıcaklıklarında yapılması fren etkinlik kaybının daha net gözlemlenmesi firsatı verecektir.

\section{KAYNAKLAR (REFERENCES)}

1. T.C. Ulaştırma, Denizcilik ve Haberleşme Bakanlığı Karayolları Genel Müdürlüğü, Trafik Kazaları Özeti-2011, Trafik Güvenliği Dairesi Başkanlığı Trafik Güvenliği Eğitimi ve Proje Şubesi Müdürlüğü, Ankara, 1-16, 2012.

2. Leeming, D.J. ve Hartley, R., Heavy Vehicle Technology, Hutchinson Education, London, England, 1981.

3. Abu Bakar, A.R., Ouyang, H., Khai, L.C. ve Abdullah, M.S., "Thermal analysis of a disc brake model considering a real brake pad surface and wear", Int. J. Vehicle Structures \& Systems, Cilt 2, No 1, 20-27, 2010.

4. Aleksendric, D., Jakovljevic, Z. ve Cirovic, V., "Intelligent control of braking process", Expert Systems with Applications, No 39, 1175811765, 2012.

5. Altıparmak, D. ve Koca, A., "Taşıtlarda tekerlek kilitlenmesi ve kaymasının durma mesafesi ve kararlılığa etkisi", Teknoloji, Cilt 1, No 2, 47$58,2001$.
6. Oppenheimer, P., "Comparing stopping capabilitiy of cars with and without antilock braking systems (ABS)", SAE, No 880324, 1988.

7. Düzgün, M., Altıparmak, D. ve Bayrakçeken, H., "An experimental investigation of stopping distance of automobiles", G.U. Journal of Science, Cilt 18, No 1, 153-165, 2005.

8. Hosseinlou, M.H., Ahadi, H. ve Hematian, V., "A study of the minimum safe stopping distance between vehicles in terms of braking systems, weather and pavement conditions", Indian Journal of Science and Technology, Cilt 5, Say1 10, 2012.

9. Bayrakçeken, H. ve Altıparmak, D., "Design of a Brake Test Equipment and Brake Force Measurement and Modelling", J. Fac. Eng. Arch. Gazi Univ., Vol.22, No.1, 21-26, 2007.

10. Valvano, T. ve Lee, K., "An analytical method to predict thermal distortion of brake rotor", SAE, No 2000-01-0445, 2000.

11. Qi, H.S. ve Day, A.J., "Investigation of disc/pad interface temperatures in friction braking", Wear, No 262, 505-513, 2007.

12. Lee, K., "Numerical prediction of brake fluid temperature rise during braking and heat soaking”, SAE, No 1999-01-0483, 1999.

13. Aleksendric, D., Barton, D.C. ve Vasic, B., "Prediction of brake friction materials recovery performance using artificial neural networks", Tribology International, No 43, 2092-2099, 2010.

14. Artus, S., Cocquempot, V., Staroswiecki, M., Hayat, S. ve Covo, C., "Temperature estimation of CHV brake discs using an energy balance approach", 2004 IEEE Intelligent Transportation Systems Conference, Washington D.C., USA, 390-395, 2004.

15. El-Tayeb, N.S.M. ve Liew, K.W., "On the dry and wet sliding performance of potentially new frictional brake pad materials for automotive industry", Wear, No 266, 275-287, 2009.

16. Neis, P.D., Ferreira, N.F. ve, Lorini, F.J., "Contribution to perform high temperature tests (fading) on a laboratory-scale tribometer", Wear, No 271, 2660-2664, 2011.

17. Satapathy, B.K. ve Bijwe, J., "Performance of friction materials based on variation in nature of organic fibres Part I. Fade and recovery behaviour", Wear, No 257, 573-584, 2004.

18. Bijwe, J., Nidhi, Majumdar, N. ve Satapathy, B.K., "Influence of modified phenolic resins on the fade and recovery behavior of friction materials", Wear No 259, 1068-1078, 2005.

19. Aleksendric, D. ve Duboka, C., "Fade performance prediction of automotive friction materials by means of artificial neural networks", Wear, No 262, 778-790, 2007.

20. Lingman, P., Integrated brake control, downhill driving strategies, Thesis for the 
Degree of Doctor of Philosophy, Calmers University of Technology, Department of Applied Mechanics, Göteborg, Sweden, 2005.

21. Ilm, A., Leung, P.S., Data, P.K., "Experimental investigations of disc brake friction", $S A E$, 2000-01-2778, 2000.

22. Erdem, M., Motorlu taşıtlarda yavaşlatıcı etkilerinin deneysel analizi ve yapay sinir ağları ile modellenmesi, Doktora Tezi, Gazi Üniversitesi Fen Bilimleri Enstitüsü, Ankara, 2007.
23. Limpert, R., "Brake Design And Safety", Second Edition, Society of Automotive Engineers, Inc, USA, 1999.

24. Heisler, H., "Advanced Vehicle Technology", British Library Cataloguing in Publication Data, Great Britain, 1989.

25. Singh, O.P., Mohan, S., Venkata Mangaraju, K., Jayamathy, M. ve Babu, R., "Thermal seizures in automotive drum brakes", Engineering Failure Analysis, No 17, 1155-1172, 2010 